\title{
Front Matter: Volume 10021
}

, "Front Matter: Volume 10021," Proc. SPIE 10021, Optical Design and Testing VII, 1002101 (23 January 2017); doi: 10.1117/12.2266328

SPIE. Event: SPIE/COS Photonics Asia, 2016, Beijing, China 


\title{
PROCEEDINGS OF SPIE
}

\section{Optical Design and Testing VII}

\author{
Yongtian Wang \\ Tina E. Kidger \\ Kimio Tatsuno \\ Editors
}

\section{2-13 October 2016 \\ Beijing, China}

Sponsored by

SPIE

COS_Chinese Optical Society

Cooperating Organizations

Tsinghua University (China) - Peking University (China) • University of Science and Technology of China (China) • Zhejiang University (China) - Tianjin University (China) - Beijing Institute of Technology (China) • Beijing University of Posts and Telecommunications (China) - Nankai University (China) - Changchun University of Science and Technology (China) • University of Shanghai for Science and Technology (China) • Capital Normal University (China) - Huazhong University of Science and Technology (China) - Beijing Jiaotong University (China) • Shanghai Institute of Optics and Fine Mechanics (China) - Changchun Institute of Optics and Fine Mechanics (China) • Institute of Semiconductors (China) • Institute of Optics and Electronics (China) • Institute of Physics (China) • Shanghai Institute of Technical Physics (China) - China Instrument and Control Society (China) - Optoelectronics Technology Committee, COS (China) • SPIE National Committee in China (China) • Optical Society of Japan (Japan) • Optical Society of Korea (Korea, Republic of) • The Australian Optical Society (Australia) • Optics and Photonics Society of Singapore (Singapore) • European Optical Society

Supporting Organizations

CAST-China Association for Science and Technology (China)

NSFC-National Nature Science Foundation (China)

Published by

SPIE

Volume 10021

Proceedings of SPIE 0277-786X, V. 10021

SPIE is an international society advancing an interdisciplinary approach to the science and application of light.

Optical Design and Testing VII, edited by Yongtian Wang, Tina E. Kidger,

Kimio Tatsuno, Proc. of SPIE Vol. 10021, 1002101 - (c) 2016 SPIE

CCC code: $0277-786 \mathrm{X} / 16 / \$ 18 \cdot$ doi: $10.1117 / 12.2266328$

Proc. of SPIE Vol. 10021 1002101-1 
The papers in this volume were part of the technical conference cited on the cover and title page. Papers were selected and subject to review by the editors and conference program committee. Some conference presentations may not be available for publication. Additional papers and presentation recordings may be available online in the SPIE Digital Library at SPIEDigitallibrary.org.

The papers reflect the work and thoughts of the authors and are published herein as submitted. The publisher is not responsible for the validity of the information or for any outcomes resulting from reliance thereon.

Please use the following format to cite material from these proceedings:

Author(s), "Title of Paper," in Optical Design and Testing VII, edited by Yongtian Wang, Tina E. Kidger, Kimio Tatsuno, Proceedings of SPIE Vol. 10021 (SPIE, Bellingham, WA, 2016) Six-digit Article CID Number.

ISSN: 0277-786X

ISSN: 1996-756X (electronic)

ISBN: 9781510604612

ISBN: 9781510604629 (electronic)

Published by

SPIE

P.O. Box 10, Bellingham, Washington 98227-0010 USA

Telephone +1 3606763290 (Pacific Time) · Fax +1 3606471445

SPIE.org

Copyright (c) 2016, Society of Photo-Optical Instrumentation Engineers.

Copying of material in this book for internal or personal use, or for the internal or personal use of specific clients, beyond the fair use provisions granted by the U.S. Copyright Law is authorized by SPIE subject to payment of copying fees. The Transactional Reporting Service base fee for this volume is $\$ 18.00$ per article (or portion thereof), which should be paid directly to the Copyright Clearance Center (CCC), 222 Rosewood Drive, Danvers, MA 01923. Payment may also be made electronically through CCC Online at copyright.com. Other copying for republication, resale, advertising or promotion, or any form of systematic or multiple reproduction of any material in this book is prohibited except with permission in writing from the publisher. The CCC fee code is 0277-786X/16/\$18.00.

Printed in the United States of America.

Publication of record for individual papers is online in the SPIE Digital Library.

\section{SPIE. DIGITAL}

Paper Numbering: Proceedings of SPIE follow an e-First publication model. A unique citation identifier (CID) number is assigned to each article at the time of publication. Utilization of CIDs allows articles to be fully citable as soon as they are published online, and connects the same identifier to all online and print versions of the publication. SPIE uses a seven-digit CID article numbering system structured as follows:

- The first five digits correspond to the SPIE volume number.

- The last two digits indicate publication order within the volume using a Base 36 numbering system employing both numerals and letters. These two-number sets start with 00, 01, 02, 03, 04, $05,06,07,08,09,0 A, 0 B \ldots$. OZ, followed by 10-1Z, 20-2Z, etc. The CID Number appears on each page of the manuscript. 


\title{
Contents
}

\author{
vii Authors \\ ix Symposium Committees \\ xi Conference Committee \\ xiii Introduction
}

SESSION 1 NOVEL OPTICAL SYSTEM DESIGN

1002104 Efficient stimulated Raman scattering in hybrid liquid-silica fibers for wavelength conversion (Invited Paper) [10021-1]

1002105 Diffractive optical elements for multi-dimensional subdiffraction-limit spot generation: design, demonstration, and characterization (Invited Paper) [10021-2]

1002106 The development of an adaptive optics system and its application to biological microscope (Invited Paper) [10021-3]

1002109 Chromostereopsis in "virtual reality" adapters with electrically tuneable liquid lens oculars [10021-6]

\section{SESSION 2 IMAGING AND DISPLAY SYSTEMS}

10021 OA Aberration vignetting phenomena and its visualization in wide angular objectives (Invited Paper) [10021-7]

10021 OB Single-pixel imaging by Hadamard transform and its application for hyperspectral imaging (Invited Paper) [10021-8]

10021 OC Geometrical waveguide in see-through head-mounted display: a review (Invited Paper) [10021-9]

\section{SESSION 3 DESIGN AND FABRICATION METHODS}

10021 OF Multi-tool design and analysis of an automotive HUD (Invited Paper) [10021-12]

$100210 G$ Optical processing deep inside optical materials using counterpropagating pulse-shaped spatial solitons (Invited Paper) [10021-13]

$10021 \mathrm{OH} \quad$ An integrated solution for compression-molded glass lenses [10021-14] 
10021 ol Two-dimensional analytical modeling of a linear variable filter for spectral order sorting [10021-15]

10021 0J Application of Q-type aspheric surface in the design of Wynne-Dyson projection lens [10021-16]

\section{SESSION 4 FREEFORM OPTICS AND OPTIMIZATION}

10021 OK Direct design of laser-beam shapers, zoom-beam expanders, and combinations thereof (Invited Paper) [10021-17]

10021 OL Optimization of aspheric multifocal contact lens by spline curve (Invited Paper) [10021-18]

10021 OM Design and verification of a flat-field aberration-corrected concave blaze grating for hyperspectral imaging [10021-19]

10021 ON Aspheric and free-form surfaces test with non-null sub-aperture stitching [10021-20]

1002100 Design of freeform unobscured reflective imaging systems using $\mathrm{Cl}$ method [10021-21]

\section{SESSION 5 CORE DEVELOPMENT AND ILLUMINATION OPTICS}

10021 OP Optical legacy of Imperial College London (Invited Paper) [10021-22]

$100210 Q \quad$ Illumination analysis of LAPAN's IR micro bolometer [10021-23]

10021 OT Visual analysis of the computer simulation for both imaging and non-imaging optical systems [10021-26]

\section{SESSION 6 MICROSCOPY AND INTERFEROMETRY}

$100210 U$ Self-mixing interferometry and its applications (Invited Paper) [10021-27]

10021 OV Measurement of optical system aberrations based on randomly encoded hybrid grating [10021-28]

POSTER SESSION

10021 OX Spatial distribution of current density and thermal resistance of high-power AllnGaN "vertical" and "face-up" light-emitting diodes [10021-31]

$100210 Z$ Study on the characteristics of novel optical phase array based on waveguide [10021-33]

1002110 Stray light analysis on helicopter optical landing guidance system [10021-34]

1002111 Improved algorithm of ray tracing in ICF cryogenic targets [10021-35] 
1002112 An improved NAS-RIF algorithm for image restoration [10021-36]

1002113 Optimization technique of wavefront coding system based on ZEMAX externally compiled programs [10021-37]

1002114 Research on characteristic of radiometric imaging quality for space-borne camera with super-wide field of view [10021-38]

1002115 Multifocal intraocular lens to correct presbyopia [10021-39]

1002116 Simulation of the BSDF measurement capabilities for various materials with GCMS-4 goniospectrophotometer [10021-41]

1002117 Image amplification based super-resolution reconstruction procedure designed for wavefront-coded imaging system [10021-42]

1002119 Full-field calibration and compensation of lateral chromatic aberration based on unwrapped phase [10021-44]

10021 1A A design of panoramic lens system to realize the projection from the local annular object field to rectangular image field by using freeform surfaces [10021-45]

10021 1D Three-dimensional illumination system for tomographic particle image velocimetry [10021-48]

10021 IG Slope error tolerance analysis for candela distribution of total-internal-reflection collimating lens [10021-51]

1002111 Simultaneous null test of primary mirror and tertiary mirror in off-axis three-mirror optical system [10021-53]

10021 1K Characterization on the effect of linear stress birefringence in a total reflection prism (TRP) ring resonator [10021-55]

10021 1M Research on detecting plankton based on darkfield microscopy [10021-57]

$100211 \mathrm{~N}$ Design, assembly, and metrology of an oil-immersion microscope objective with long working distance [10021-58]

1002110 Tilt displacement range testing for a piezoelectric deformable mirror [10021-59]

10021 IP Optical design of Offner-Chrisp imaging spectrometer with freeform surfaces [10021-60]

10021 1Q Design of a holographic waveguide with L configuration [10021-63]

10021 IR Design and analysis of conical diffraction imaging spectrometer with high spectral resolution and wide spectral dispersion range [10021-65]

10021 is Design of refractive fore-optics with wide field of view and waveband for miniature imaging spectrometer [10021-66] 
10021 iT Afocal three-mirror anastigmat with zigzag optical axis for widened field of view and enlarged aperture [10021-67]

$100211 \mathrm{~V}$ Optical design of a dual-channel two-focal-length system by utilizing azimuth property of PAL structure [10021-70]

$10021 \mathrm{lW}$ The study of $700 \mathrm{~mm}$-diameter primary mirror based on topology optimization and sensitivity analysis [10021-71]

10021 1X Wave-front sensing for sparse aperture imaging system based on the sub-aperture phase diversity [10021-72]

10021 IY Depolarization of laser beam propagating through atmosphere based on multiple Rayleigh scattering model [10021-73]

1002112 Mean likelihood estimation of target micro-motion parameters in laser detection [10021-74]

1002120 Research on focusing properties of multi-vortex phases vector beams loading with different topological charges [10021-75]

1002121 Design of photonic crystal Fizeau interferometer using self-collimation effect [10021-76]

1002122 Light concentrator of the wide field-of-view Cherenkov telescope [10021-77]

1002124 The water colority measurement based on HSV chromaticity [10021-79]

1002125 Tomato seeds maturity detection system based on chlorophyll fluorescence [10021-80]

1002128 Demonstration of DFTS-OFDM and equalization technology using in VLC communication on the headset port of Android device [10021-83]

1002129 An interactive VR system based on full-body tracking and gesture recognition [10021-84] 


\title{
Authors
}

Numbers in the index correspond to the last two digits of the six-digit citation identifier (CID) article numbering system used in Proceedings of SPIE. The first four digits reflect the volume number. Base 36 numbering is employed for the last two digits and indicates the order of articles within the volume. Numbers start with 00, 01, 02, 03, 04, 05, 06, 07, 08, 09, 0A, 0B...0Z, followed by 10-1Z, 20-2Z, etc.

\author{
A., Bustanul, $O Q$ \\ Aladov, A. V., OX \\ Bai, Jian, ON \\ Bai, Zhaoguang 14 \\ Barladian, B. K., OT \\ Berzinsh, Janis, 09 \\ Bi, Chao, IK \\ Bian, Xuqi, $1 \mathrm{~A}$ \\ Birukov, E. D., OT \\ Chakraborty, Symphony, 01 \\ Chang, Jun, 11 \\ Chen, Baohua, $1 \mathrm{X}$ \\ Chen, Chao-Chang A., OL \\ Chen, Duo, 29 \\ Chen, $\mathrm{Hua}, \mathrm{OH}$ \\ Chen, Weilin, 11 \\ Chen, Wen, $0 z$ \\ Cheng, Dewen, 0C, IV \\ Cheng, Xuemin, 10 \\ Chernyakov, A. E., OX \\ Chi, Nan, 28 \\ Delaye, Philippe, 04 \\ $\mathrm{Di}$, Guodong 14 \\ Dong, Liquan, 13 \\ Duerr, Fabian, OK \\ Fan, Fan, 10 \\ Fan, Junliu, 1X, 24 \\ Fan, Yuanlong, OU \\ Feng, Lei, 1P, IW \\ Galaktionov, Vladimir A., 16 \\ Gao, Feng, 19 \\ Gao, Weizhe, 12 \\ Garbul, Alexey A., 16 \\ Guo, Buyu, 1M \\ Guo, Liren, 12 \\ Guo, Nan, 29 \\ Han, Libo, 13 \\ Han, Lin $1 T$ \\ Hao, Qun, 10 \\ Hao, Shiqi, $1 Y$ \\ Hasenaver, David, OF \\ Hattori, Masayuki, 06 \\ He, Anzhi, ID \\ $\mathrm{He}$, Xiaoying, IW \\ Hisaka, Masaki, OG \\ $\mathrm{Ho}$, Cheng-Fang, OJ, $1 \mathrm{~N}$ \\ Hong, Chi-Tsung, Ol, OM \\ Hou, Qichao, OC \\ Hou, Rui, IM
}

Hou, Wei, 00

Hsiao, Chiu-Der, Ol, OM

Hsu, Wei-Yao, OJ, IN

Hu, Yihua, $1 Z$

Huang, Shujun, 19

Huang, Yifan, 10

Irving, Bruce, OF

Iwata, Tetsuo, OB

Ji, Yunjing, 1D

Jiang, Jiabin, OV, 11

Jiang, Lai, 15

Jiang, Xiangqian, 19

Jiang, Yajun, $1 \mathrm{~K}$

Jin, Guofan, 00

Jin, Yangming, IR, IT

Jing, Juanjuan, 1P, IW

Kidger Webb-Moore, Tina E., OP

Ko, Cheng-Hao, Ol, OM

Kuo, Hui-Jean, IN

Kuptsov, V. D., OX

Lebrun, Sylvie, 04

Letunovskaya, Marina, OA

Li, Cuiling, 25

Li, Dong, $1 \mathrm{~K}$

Li, Heng, 10

Li, Hengnian, 12

Li, Li-jing, $\mathrm{OZ}$

Li, Lin, 10

Li, Qi, $1 T$

Li, Wen-Qiang, 1Q

Li, Yacan, 1P, IW

$\mathrm{Li}$, Yangyang 10

Li, Zhenhua, 1D

Liao, BoLin, 22

Lien, $\mathrm{Vu}$. T. OL

Lin, Wen-Lung, $1 \mathrm{~N}$

Ling, Tong, OV, 11

Liu, Bin, OU

Liv, Changhai, 12

Liu, Dong, ON

Liu, Huiping, $1 M$

Liu, Ming, 13

Liv, Qinghan, 1R, 1S

Liu, Xiaohong, 19

Liv, Xiaohua, 13

Liu, Xiaoying, $1 \mathrm{M}$

Liv, Yongji, 15

Livshits, Irina, OA

Lu, Chunling 14 
Lu, Zhiyi, $1 \mathrm{X}$

Luo, Tao, IG

Ma, Tao, $1 \mathrm{~A}$

Mao, Jingchao, is

Meng, Zhijun, 25

Mizutani, Yasuhiro, OB

Muizniece, Kristine, 09

Mulder, Steve, OF

Niu, Yajun, 11

Ogura, Yusuke, 05

Okishev, Sergey, OA

Ozolinsh, Maris, 09

P., Irwan, OQ

Pan, Qiao, $1 \mathrm{R}$

Pan, Yang, 24

Pauliat, Gilles, 04

Peng, Wei-Jei, 0J, $1 \mathrm{~N}$

Phan Huy, Minh-Châu, 04

Potemin, Igor S., OA, OT, 16

Qiu, Yu-Ting, OL

Qu, Xiangju, 1D

Sang, Xinzhu, 29

Shapiro, L. S., OT

Shen, Benlan, 11

Shen, Weimin, 1R, 1S, 1T

Shen, Yibing, ON

Sheng, XiYi, 22

Shi, Meng, 28

Shi, Tu, ON

Shibuya, Kyuki, OB

Sokolov, Vadim G., 16

Song, Yang, 1D

Song, Yong, 10

T., Andi M., OQ

Taguchi, Hiroki, OB

Takaya, Yasuhiro, OB

Tamada, Yosuke, 06

Tanida, Jun, 05

Tao, Bo, $\mathrm{OH}$

Thienpont, Hugo, OK

Tsai, Jih-Run, OI, OM

Tsai, Sheng-Yu, OI, OM

Valiev, I. V., OT

Valyukhov, V.P., OX

Voloboy, Alexey G., OT, 16

Wang, Bang-Ji, OI, OM

Wang, Dongdong, 10

Wang, Fan, 24

Wang, Fumin, 28

Wang, Gang, $1 G$

Wang, Jun, 1X, 21, 24

Wang, Kuiru, 29

Wang, Lei, $1 Y$

Wang, Peng, 29

Wang, Qiwei, OC

Wang, Wei, 1 W

Wang, Xiaolin, 15

Wang, Xin, $1 \mathrm{~W}$

Wang, Xiu, 25

Wang, Yongtian, OC, IV
Wang, Yunpeng, 12

Wang, Zhaogi, 15

Wang, Zhenya, $1 \mathrm{X}$

Wei, Jingxuan, 17

Wei, Lidong, IP, IW

Wu, Bin, 14

Wu, Quanying, 1X, 24

Wu, Xiaofei, 00

Wu, Xiaoging, 14

Wu, Yueh-Hsun, Ol, OM

Xiang, Guangxin-Xin, 1Q

Xie, Xiaopeng, 17

$\mathrm{Xu}$, Chen, IV

$\mathrm{Xu}$, Minyi, $1 \mathrm{~S}$

$X \cup$, Qingshan, 14

$\mathrm{XU}$, Rong, 12

Yan, Binbin, 29

Yang, Rui, 22

Yang, Tong, 00

Yang, Xiaoping, 20

Yang, Yongying, ON, OV, 11

Yasui, Takeshi, OB

Ye, Jia-Yu, OZ

Yin, Huan, 14

Yu, Jia, $1 \mathrm{M}$

Yu, Yanguang, OU

Yuan, Xiao, 21

Yuan, $\mathrm{Ye}, \mathrm{OH}$

Zakgeim, A. L., OX

Zeng, Xia, 29

Zhang, Dai, $1 Y$

Zhang, Fen, 1D

Zhang, Jun, IA

Zhang, Lei, ON

Zhang, Rui, OV, 11

Zhang, Xianyi, 20

Zhang, Zonghua, 19

Zhao, Hui, 17

Zhao, Jianlin, $1 \mathrm{~K}$

Zhao, Qi, 1 Y

Zhao, Yuejin, 13

Zhao, Zhicheng, IR

Zhdanov, Dmitry D., OA, OT, 16

Zhou, Jinsong, IP, IW

Zhou, Xinlin, $\mathrm{OH}$

Zhou, Yuhao, $0 \mathrm{~N}$

Zhu, Jun, 00, 14

Zhu, Lin, 14

Zong, Caihui, 17

Zou, Jianhua, 12 


\title{
Symposium Committees
}

\author{
General Chairs
}

Robert Lieberman, SPIE President, Lumoptix, LLC (United States)

Guangcan Guo, Chinese Optical Society President, University of Science and Technology of China (China)

General Co-chairs

Arthur Chiou, National Yang-Ming University (Taiwan, China)

Jianlin Cao, China Ministry of Science and Technology (China)

Junhao Chu, Shanghai Institute of Technical Physics (China)

Technical Program Chairs

Songlin Zhuang, University of Shanghai for Science and Technology

(China)

Xingde Li, Johns Hopkins University (United States)

Technical Program Co-chairs

Bingkun Zhou, Tsinghua University (China)

Qiming Wang, Institute of Semiconductors (China)

Tianchu Li, National Institute of Metrology (China)

Wei Huang, Nanjing University of Technology (China)

Ying Gu, PLA General Hospital (China)

Huilin Jiang, Changchun University of Science and Technology

(China)

Local Organizing Committee Chair

Qihuang Gong, Peking University (China) 
Local Organizing Committee Co-chairs

Xu Liu, Zhejiang University (China)

Daoyin Yu, Tianjin University (China)

Guoqiang Ni, Beijing Institute of Technology (China)

Shusen Xie, Fujian Normal University (China)

Xiaomin Ren, Beijing University of Posts and Telecommunications

(China)

General Secretary

Yan Li, Chinese Optical Society/Peking University (China)

Local Organizing Committee

Zhiping Zhou, Peking University (China)

Changhe Zhou, Shanghai Institute of Optics and Fine Mechanics, CAS

(China)

Qingming Luo, Huazhong University of Science and Technology

(China)

Chongxiu Yu, Beijing University of Posts and Telecommunication

(China)

Hongda Chen, Institute of Semiconductors (China)

Yongtian Wang, Beijing Institute of Technology (China)

Yiping Cui, Southeast University (China)

Xuping Zhang, Nanjing University (China)

Feijun Song, Daheng Corporation (China)

Cunlin Zhang, Capital Normal University (China)

Yanting Lu, Nanjing University (China)

Yuejin Zhao, Beijing Institute of Technology (China)

Chunqing Gao, Beijing Institute of Technology (China)

Tiegen Liu, Tianjin University (China)

Xiaocong Yuan, Nankai University (China)

Weimin Chen, Chongqing University (China)

Zhongwei Fan, Academy of Optoelectronics (China)

Hanyi Zhang, Tsinghua University (China)

Lan Wu, Zhejiang University (China)

Yongsheng Zhang, University of Science and Technology of China (China)

Hong Yang, Peking University (China)

Xiaoying Li, Tianjin University (China)

Wei Xiong, Chinese Optical Society (China) 


\section{Conference Committee}

Symposium Chairs

Robert A. Lieberman, Lumoptix, LLC (United States)

Wei Xiong, Chinese Optical Society (China)

Conference Chairs

Yongtian Wang, Beijing Institute of Technology (China)

Tina E. Kidger, Kidger Optics Associates (United Kingdom)

Kimio Tatsuno, Koga Research Institute, Ltd. (Japan)

Conference Program Committee

Yasuhiro Awatsuji, Kyoto Institute of Technology (Japan)

Jian Bai, Zhejiang University (China)

Pablo Benítez, Universidad Politécnica de Madrid (Spain)

Toshihide Dohi, OptiWorks, Inc. (Japan)

Chunlei Du, Chongqing Institute of Green and Intelligent Technology (China)

Fabian Duerr, Vrije Universiteit Brussel (Belgium)

Yi-Chin Fang, National Kaohsiung First University of Science and Technology (Taiwan, China)

Sen Han, University of Shanghai for Science and Technology (China)

Qun Hao, Beijing Institute of Technology (China)

Hong Hua, College of Optical Sciences, The University of Arizona

(United States)

Dong Hoon Hyun, Korea Polytechnic University (Korea, Republic of)

Byung Yun Joo, Korea University of Technology and Education

(Korea, Republic of)

Michael Kim, Modern High-Tech Company, Ltd. (Korea, Republic of)

Tsuyoshi Konishi, Osaka University (Japan)

Yanqiu Li, Beijing Institute of Technology (China)

Irina L. Livshits, ITMO University (Russian Federation)

Osamu Matoba, Kobe University (Japan)

Xiang Peng, Shenzhen University (China)

Jannick P. Rolland, University of Rochester (United States)

Jae Myung Ryu, Kumoh National Institute of Technology

(Korea, Republic of)

José Sasián, College of Optical Sciences, The University of Arizona

(United States)

Qiaofeng Tan, Tsinghua University (China)

Sandy To, The Hong Kong Polytechnic University (Hong Kong, China)

Theo Tschudi, Technische Universität Darmstadt (Germany) 
Wilhelm Ulrich, Carl Zeiss AG (Germany)

H. Paul Urbach, Technische Universiteit Delft (Netherlands)

David M. Williamson, Nikon Research Corporation of America

(United States)

\section{Session Chairs}

1 Novel Optical System Design

Kimio Tatsuno, Koga Research Institute, Ltd. (Japan)

2 Imaging and Display Systems

Irina L. Livshits, ITMO University (Russian Federation)

3 Design and Fabrication Methods

Yongtian Wang, Beijing Institute of Technology (China)

4 Freeform Optics and Optimization

Tina E. Kidger, Kidger Optics Associates (United Kingdom)

5 Core Development and Illumination Optics

Fabian Duerr, Vrije Universiteit Brussel (Belgium)

6 Microscopy and Interferometry

Gilles Pauliat, Institut d'Optique Graduate School (France) 


\section{Introduction}

The official SPIE/COS (the Chinese Optical Society) partnership was inaugurated in 1990 with the signing of a joint partnership agreement. Since that time, more than twenty-five years ago, there have been numerous joint conferences including this most recent Photonics Asia symposium. Photonics Asia represents one of the several recognized periodic events allowing all members of the optical engineering and photonics community to interact and network in a synergistic and beneficial manner. It is a true sign of cooperation and friendship between optical community members which more than satisfies the aspirations envisioned by the original SPIE/COS agreement. As the Optical Design and Testing VII cochairs, we are pleased to have had the opportunity to assist in the further evolution and development of this continuing enhancement of the optical engineering community.

It is without doubt to call the "Optical Design and Testing VII" conference portion of the SPIE/COS Photonics Asia 2016 symposium a complete success. The conference consisted of six sessions, twenty-nine oral presentations and forty-nine posters. Of the twenty-nine scheduled oral presentations, five were 'no-shows' leaving twenty-four papers actually presented over one day and a half. Five 'noshows' is not an unusual number given the international nature of the conference and the travel and schedule complications thereby imposed. Topics covered in the conference covered a broad range including system design, imaging, display, fabrication, freeform optics, illumination and interferometry. Paper quality was generally above average and represented considerable research and development energy. The audience appeared deeply engrossed in all the presentations and certainly appreciated the tremendous time and effort put forth by all the presenters, including those who were not able to be physically present for various reasons.

We wish to thank all the participants in Optical Design and Testing VII for helping to make this conference the success it was. Looking forward to the next Photonics Asia symposium, it is hoped that continual technical and scientific advancement will be available for presentation and that the participants in this meeting will be able to return along with additional contributing optical scientists and engineers to help make the next and future conferences even more successful than this one.

\section{Yongtian Wang Tina E. Kidger Kimio Tatsuno}


Proc. of SPIE Vol. 10021 1002101-14 Downloaded From: https://www.spiedigitallibrary.org/conference-proceedings-of-spie on 26 Apr 2023
Terms of Use: https://www.spiedigitallibrary.org/terms-of-use 